\title{
COMBINING AHP GROUP ANALYSIS AND GIS IN VULNERABILITY ASSESSMENT OF PROTECED AREA IN VIETNAM
}

\author{
Nghiem Quynh Huong \\ Institute of Geography and Geology \\ University of Greifswald \\ Greifswald, Germany \\ E-mail: nghiem.q.huong@gmail.com
}

\begin{abstract}
In land use resources, forests play an important role in mitigating climate change by reduce carbon uptake through afforestation as well as sustainable forest management. Vietnam is viewed as a "country in transition" with a "biodiversity hot spot" because many strange mammals have been discovered by scientists (McElwee, 2001). In the process of rapid social-economic development, Vietnam is facing many problem such as the conflict between the need of reduce poverty and the need of protect biodiversity. This research assess vulnerability of Bach Ma National Park (BMNP) - a protected area in central Vietnam - using spatial multi-criteria decision analysis and application of Geographic Information System (GIS). Expert interviews from different background are identified in order to establish AHP - group decision making framework. Different AHP results from individual judgments are then aggregated into a group decision to support the final decision making for vulnerability assessment. Data are processed and analyzed with help of ArcGIS to determine the spatial distribution of vulnerable areas in the National Park.
\end{abstract}

Keywords: Multi-criteria decision analysis, AHP, AHP - group decision making (AHPGDM), GIS, protected area, vulnerability assessment.

\section{Introduction}

Decision-making plays a very important role in many fields in life. There are many problems that will appear in life. Each of us ourselves in fact is a decision-maker. And our goal is how to get the best way to solve/reduce all problems. A wrong decision may lead to bad or even more terrible consequences. That's why we need a good decision support system (DSS) to design the best solution in each situation. The Analytic Hierarchy Process (AHP) is developed by Saaty, T. and up to now AHP has been widely applied in many fields in the real world such as economy, human resources management, land use planing, risk assessment, environment, etc.

In environmental assessment, the multi-criteria decision making method is a very strong tool. The research used AHP methodology and combine with GIS to show the real spacial distribution of vulnerable areas in protected area. 
Established in 1991, Bach Ma National Park's area (BMNP) is 22,031ha with an effort to conserve the left forest's resources from exploitation in Vietnam which caused rigorous deforestation at that time. In 2008, the Prime Minister of Vietnam signed the Decision 01/QD-TTg to enlarge BMNP toward 37,487ha. BMNP is important for conservation of a green transect, stretching from Lao's border to the East See. Bach Ma is one of two unique new reference sites in Vietnam that are both a "pilot model about sharing benefit in management, protection and sustainable development of special-use forest". Currently, BMNP is facing with problems of financial shortage for its forest protection tasks such as to combating deforestation and degradation. The main causes of this forest degradation are by human activities such as illegal logging and illegal hunting. The results of this study will be essential to forecast and prevent environmental risks, and to contribute to sustainable resource management and human activities.

\section{Literature Review}

Problem is structured as a hierarchy. The Analytic Hierarchy Process (AHP) was proposed by Thomas Saaty (Saaty, 1980a). This is a multi-criteria decision method that used hierarchical structures to represent a problem and then develop priorities for alternatives based on the judgment of the user (Saaty, 1980b). The AHP is a theory of measurement through pairwise comparisons and relies on the judgments of experts to derive priority scales. There are four ways to combine preferences (Ishizaka, 2011):

\begin{tabular}{llll}
\hline & \multicolumn{2}{l}{ Mathematical aggregation } \\
\cline { 3 - 4 } & Yes & No \\
\hline $\begin{array}{l}\text { Aggregation } \\
\text { on: }\end{array}$ & Judgments & $\begin{array}{l}\text { Geometric mean on } \\
\text { judgments }\end{array}$ & $\begin{array}{l}\text { Consensus vote on } \\
\text { judgments }\end{array}$ \\
\cline { 2 - 4 } & Priorities & $\begin{array}{l}\text { Weighted arithmetic mean } \\
\text { on priorities }\end{array}$ & Consensus vote on priorities \\
\hline
\end{tabular}

However, it has been proved that the geometric mean, not the frequently used arithmetic mean, is the only way to do that (Saaty, 2008). AHP group or AHP in group decision making is a step further from individual AHP. That means its not only one judgment but several experts take part into the decision maker-group. The two important steps in AHP group are: how to combine individual judgments in a group into a single representative judgment for the entire group and how to construct a group choice from individual choices (Saaty, 2012).

Parameters that reflect vulnerability assessment should be determined and selected. After that, they are aggregated according to an appropriate set of weights. Such combinations of all the information and classification have been greatly aided by the GIS capability as well as integrated remote sensing applications. With these techniques, storing of multidisciplinary data and examining the relationships between them could be performed at various scales and in a digital format (Burrough 1986). In this study, the ArcGIS (ESRI), FME (The Feature Manipulation Engine) are mainly used.

\section{Hypotheses/Objectives \& Research Design/Methodology}

A theoretical framework of producing a general vulnerability indicator needs to include a model of vulnerability - to identify its components and their mutual dependencies, and a 
mathematical model - used to aggregate the information into a hierarchically organized set of indicators.

The method for vulnerability assessment in this research is based on environmental vulnerability index (EVI) of SOPAC (Kaly UL et al., 2005) and assessment protocol of NOAA (NOAA, 1999) which applied for situation in Vietnam.

Following that, vulnerability assessment of BMNP is defined as a function of three components:

In which,

$$
V i_{i j} j_{j}=f\left(a D x_{i} y_{j}, b V x_{i} y_{j}, c A x_{i} y_{j}\right)
$$

1) $\mathrm{Dx}_{\mathrm{i}} \mathrm{y}_{\mathrm{j}}$ : Driving forces - The total risk from natural hazards and human activities.

2) $\mathrm{Vx}_{\mathrm{i}} \mathrm{y}_{\mathrm{j}}$ : Vulnerable objects - Density and distribution of vulnerable objects (population, properties, resources, ecosystems...);

3) $\mathrm{Ax}_{\mathrm{i}} \mathrm{y}_{\mathrm{j}}$ : Adaptive capacity including objects with natural adaptive capacity and social adaptive capacity such as distance from roads, village, poverty, management effect.

$\mathrm{x}_{\mathrm{i}} \mathrm{y}_{\mathrm{j}}$ represent coordinate system and $\mathrm{a}, \mathrm{b}, \mathrm{c}$ are weight of the components.

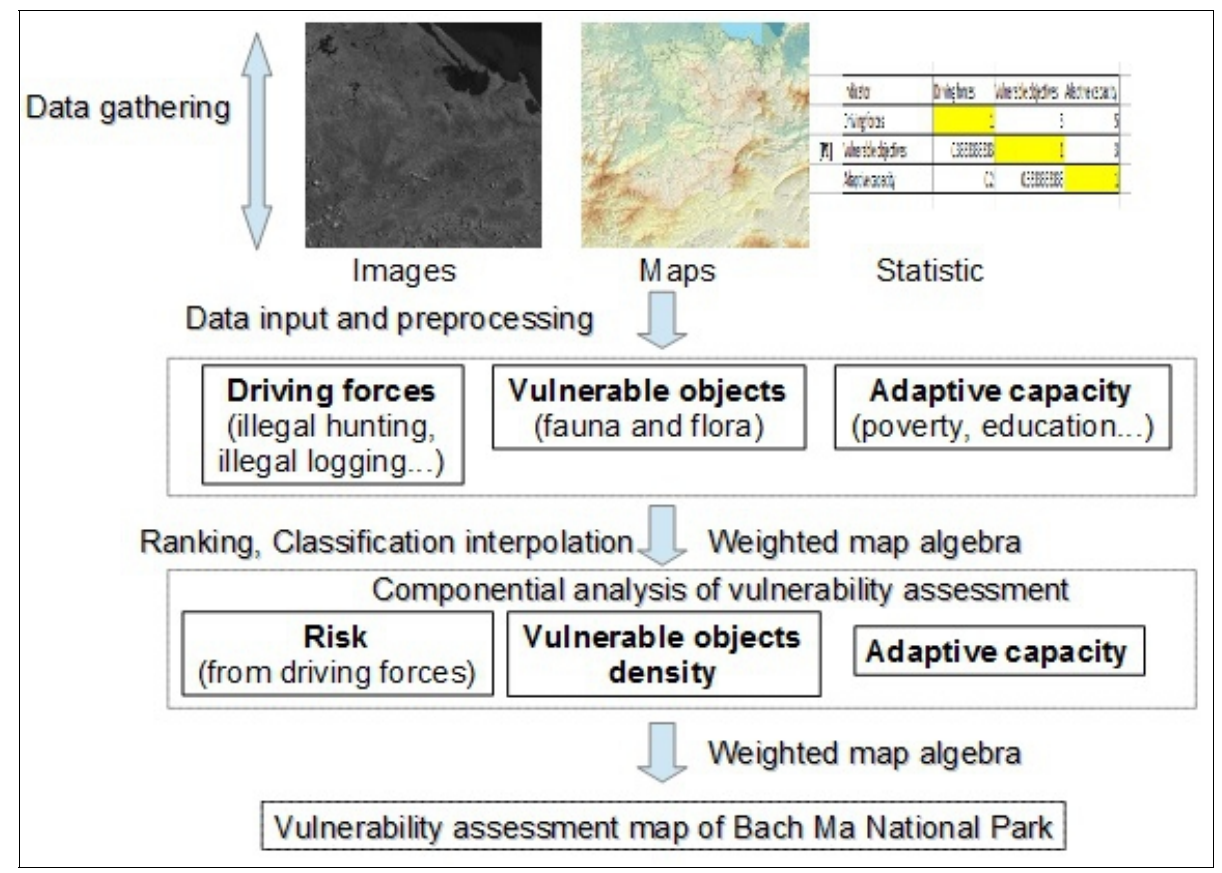

Figure 1. Applying Geographic Information System to create the components of vulnerability index for Bach Ma National Park

Nine experts are involved in process of evaluating BMNP vulnerability, including university lectures, forest rangers from the BMNP and managers of the National Park. Drafts of questionnaire are pre-tested with experts in Uni. Greifswald and staff in BMPN who working and have experience with BMNP. To choose the right experts will be interview later, it is selected by the person who involved directly or officially with the research in the case study area. Face to face interviews were carried out with experts. 


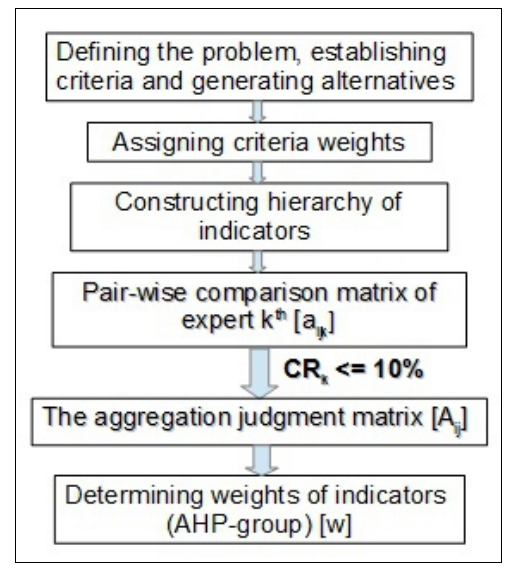

Figure 2. Aggregation of AHP group decision to determine weights of indicators (AHP-GDM): [w]

Aggregation judgment matrices of the group experts is calculated by:

$$
\mathrm{A}_{\mathrm{ij}}=\left(\prod_{k=1}^{n} a_{i j k}\right)^{1 / n}
$$

\section{Data/Model Analysis}

Each expert interview is analyzed by Excel with pair-wise comparison matrix to calculate eigenvalue $\lambda$ max, eigenvector $\omega$, consistency index (CI), and consistency ratio (CR). After calculating weights for all criteria in each expert interview, the judgment results of all 9 experts are presented in the table 1.

Table 1

Aggregation of pair-wise comparisons matrix for indicators of level 1

Level 1

\begin{tabular}{|l|l|l|l|l|l|l|l|l|l|l|l|}
\hline \multicolumn{2}{|l|}{ Indicators } & \multicolumn{7}{l|}{ Judgment of expert No. k } \\
\hline \multirow{2}{*}{$\mathrm{i}$} & $\mathrm{j}$ & 1 & 2 & 3 & 4 & 5 & 6 & 7 & 8 & 9 & $\mathrm{~A}_{\mathrm{ij}}$ \\
\hline \multirow{2}{*}{$\mathrm{DF}$} & VO & 3 & 4 & 3 & 3 & 0.333 & 0.333 & 4 & 7 & 3 & 2.156 \\
\cline { 2 - 13 } & AC & 5 & 0.5 & 5 & 5 & 3 & 3 & 3 & 2 & 5 & 2.949 \\
\hline \multirow{2}{*}{ VO } & AC & 3 & 0.2 & 1 & 1 & 5 & 5 & 2 & 0.166 & 3 & 1.351 \\
\hline \multicolumn{2}{l|}{ CR (\%) } & 0.033 & 0.021 & 0.025 & 0.025 & 0.033 & 0.033 & 0.093 & 0.028 & 0.033 & 0.032 \\
\hline
\end{tabular}

In which: DF: Driving Forces; VO: Vulnerable Objects; AC: Adaptive Capacity;

CR: Consistency Ratio.

From the calculated $\mathrm{A}_{\mathrm{ij}}$ results, table 2 shows the final result for AHP-group decision making level 1. 
Table 2

Pair-wise comparison matrix of 9 experts

Level 1

\begin{tabular}{|l|l|l|l|}
\hline Indicators & Driving forces & Vulnerable objects & Adaptive capacity \\
\hline Driving forces & 1 & 2.156 & 2.949 \\
\hline Vulnerable objects & 0.464 & 1 & 1.351 \\
\hline Adaptive capacity & 0.339 & 0.740 & 1 \\
\hline $\begin{array}{l}\text { Consistency Test } \\
(\mathrm{CR}<=10 \%)\end{array}$ & $\begin{array}{l}\text { Eigenvalue }=3.000 \rightarrow \mathrm{CI}=8.271 ; \\
\mathrm{RI}=0.58 \rightarrow \mathrm{CR}=\mathrm{CI} / \mathrm{RI}=1.43 \mathrm{E}-005\end{array}$ & \\
\hline
\end{tabular}

\section{Limitations}

That is not all of collected data could have spatial information to input to GIS. For example, not all of fauna and flora in the National Park are evaluated for vulnerability; some of them are lack of statistic information \&/ spacial distribution information. That's why vulnerable objects which selected in the research are just some of typical vulnerable fauna and flora of the BMNP. Therefore that is not all spatial distribution of vulnerable objects could be presented in vulnerability map of BMNP.

\section{Conclusions}

Databases and maps should be completed with high accuracy and maps of sensitive areas should be standardized with higher scales to get more information in detail.

After the step of AHP-group decision making, next step of the study will be combination of two techniques: the AHP-group and the fuzzy logic to create a Fuzzy AHP-Group. The final Fuzzy AHP-Group will be integrated with GIS to create a new model for handling spatial multi-criteria decision making problems. The result will contribute significantly for sustainable use of land use resources, especially, protected areas in Vietnam.

\section{Key References}

Burrough, P.A. (1986). Principles of geographic informaion systems for land resources assessment. Clarendon Press. Oxford Oxfordshire and New York (12).

Malczewski, J. (1999). GIS and Multicriteria decision analysis. John Wiley \& Sons, Inc, New York.

Saaty, T.L. (1980). Multi-criteria Decision Making: The Analytic Hierarchy Process. McGraw-Hill, New York, $2^{\text {nd }}$ printing 1990, RSW Pub. Pittsburgh.

Saaty, T.L. (2008). Decision making with the analytic hierarchy process. International Journal of services Sciences 1 (1), pp. 83-98 (16).

Saaty, T.L. (2012). The seven Pillars of the Analytic Hierarchy Process. Models, Methods, Concept \& Applications of the Analytic Hierarchy Process. International Series in Operations Research \& Management Science Volume 175, 2012, pp. 23-40. 